\title{
Prevalence and characteristics of eye involvement in patients with
}

\section{rheumatoid arthritis}

Accepted: 15/8/2016

Abstract

Background and objective: Rheumatoid arthritis is a systemic inflammatory disease. Ocular manifestations involved with rheumatoid arthritis are keratoconjunctivitis sicca, episcleritis, scleritis, anterior and posterior uveitis, dry eyes and ulcerative keratitis. This study aimed to detect the prevalence of ocular manifestations in rheumatoid arthritis patients, find out the relation between the effects of disease modifying anti-rheumatic drugs, biological agents and ocular complications in rheumatoid arthritis patients and explore role of anti-cyclic citrullinated peptide antibodies.

Methods: This is a cross-sectional clinical study of 60 rheumatoid arthritis patients who have attended Rizgary Teaching Hospital in Erbil. A data information about symptoms of ocular manifestations and history of ocular complications before starting disease modifying anti-rheumatic drugs and/or biological agents were taken. Musculoskeletal examination, serum Anti-CCP antibodies test were done. Ocular examination by ophthalmologist was done.

Results: This study was conducted from April to November 2015 and involved 60 patients; 55 females and five males with a mean \pm SD age of $46 \pm 11.46$ years. Thirty nine $(65 \%)$ patients had ocular manifestations of rheumatoid arthritis. The most frequent manifestation was dry eyes 30 (50.0\%). There was no relation between severity of the rheumatoid arthritis disease and ocular manifestation $(P=0.529)$. There was a relationship between the Anti-CCP antibodies titer and presence of ocular manifestations in rheumatoid arthritis patients $(P=0.006)$. There were no curable effects of the disease modifying anti-rheumatic drugs, biological agents on ocular manifestations in rheumatoid arthritis patients $(P=0.787)$.

Conclusion: Dry eye was the most common ocular manifestation, anti-CCP antibodies are a sensitive marker for ocular manifestations. Disease modifying anti-rheumatic drugs and biological therapies provide no significant efficacy in treatment or prevent the occurrence of ocular manifestations in rheumatoid arthritis patients.

Keywords: Rheumatoid arthritis; Anti-CCP antibodies; Dry eye.

\section{Introduction}

Rheumatoid arthritis (RA) is a chronic systemic inflammatory autoimmune disease. ${ }^{1}$ It associated with a number of extra-articular manifestations, one of them is ocular manifestations that present in $10-20 \%$ of RA patients, which are more frequent in seropositive patients. ${ }^{2}$ Ocular manifestations involved with $\mathrm{RA}$ are keratoconjunctivitis sicca, episcleritis, scleritis, sclera malacia corneal changes, and retinal vasculitis. ${ }^{3-5}$ Keratoconjunctivitis sicca is common in individuals with RA and is often the initial manifestation. ${ }^{4,5}$ Episcleritis is an inflammatory condition affecting the episcleral tissue that lies between the conjunctiva and the sclera; it is usually a mild, self-limiting, recurrent disease. Most cases are idiopathic; although up to one third have an underlying systemic condition. ${ }^{4-6}$ Scleritis is a chronic, painful, and potentially blinding

* Erbil Directorate of Health, Erbil, I raq.

** Department of internal Medicine, College of Medicine, Hawler Medical University, Erbil, I raq. 
inflammatory disease that is characterized by edema and cellular infiltration of the scleral and episcleral tissues. Sclera malacia is painless bilateral thinning of the sclera, with the affected area appearing blue or gray (the color of the underlying choroid). ${ }^{7-9} \mathrm{RA}$ is a common disorder to affect peripheral cornea. Corneal changes such as sclerosing keratitis; corneal melting is a rare but devastating manifestation, it usually occurs in long standing disease and is associated with systemic vasculitis; it causes pain, redness and blurred vision. ${ }^{9}$ Long term use of systemic corticosteroids in treatment of RA patients may induce formation of posterior subcapsular cataract and systemic steroid also increase risk of glaucoma and raised intraocular pressure. $^{10}$ One of the drugs used in treatment of RA is disease modifying anti rheumatic drugs (DMARD) including hydroxychloroquine (HCQ), this antimalarial drug used in treatment of RA usually in combination with other (DMARD), one of its side effects is corneal deposits and retinopathy. ${ }^{9}$ Anti-CCP antibodies are sensitive and specific diagnostic marker of RA especially in early cases and for systemic involvement in RA patients. The sensitivity and specificity of anti-CCP reactivity for RA patients' diagnosed based on American College of Rheumatology criteria were detected as $73.5 \%$ and $95 \%-97 \%$, respectively which shows it to be a highly sensitive and specific marker for the disease. ${ }^{11,12}$ This study was designed to detect the prevalence of ocular manifestations in RA patients, to find out the relation between the curable effects of disease modifying anti-rheumatic drugs, biological agents and ocular involvements in rheumatoid arthritis patients living in Erbil city.

\section{Methods}

This is a cross-sectional clinical study of 60 RA patients who have attended Rizgary Teaching Hospital in Erbil, was approved by the institute's ethics committee. Patients with established RA for more than six months on DMARDs\&/or biological agents attending outpatient clinics of rheumatology and physiotherapy unit were included in the study. The DMARDs that used were (methotrexate, leflunomide), and the biological agents were Anti-tumor necrosis factor- alfa drugs (etanercept, infliximab, adalimumab), which given according to American College of Rheumatology 2015 Guidelines for Rheumatoid Arthritis treatment. Patients with juvenile RA ( $<16$ years of age), dry eyes due to other diseases such as Steven-Johnson syndrome, ocular cicatriclepemphigoid, radiation and chemical injuries, patients with diabetes mellitus, patients with uveitis, scleritis, glaucoma, due to causes other than RA e like seronegative spondiloarthropathy, Bechet's disease, patients on DMARD (hydroxychloroquine) and drugs that cause ocular problems, patients on steroids with ocular complications (cataract glaucoma, increase intraocular pressure) due to the effect of steroids were excluded from the study.

\section{Statistical analysis}

Data were analyzed using the statistical package for the social sciences (version 19). Chi square test of association was used to compare between proportions. When the expected count of more than $20 \%$ of the cells of the table was less than 5 , Fisher's exact test was used. Student's $t$ test was used to compare between means of two groups. A $P$ value of $\leq 0.05$ was considered statistically significant.

\section{History}

In all cases, a detailed history related to the duration of RA, systemic manifestations of RA, drug use and duration of treatment, family history of RA, symptoms related to ocular manifestations and any history of symptoms or diagnosed ocular manifestations before starting DMARDs and/or biological agents were studied. Data were collected and recorded on a specially designed questionnaire after taking permission from the patients. 
Musculoskeletal Examination

Musculoskeletal examination was done by Rheumatologist and disease activity assessed by DAS28 score which involve counting the number of swollen and tender joints in the upper limbs and knees and combining this with the ESR and the patient's assessment of his/her general health on visual analogue scale to generate a numerical score, the higher value, the more active disease. Serum Anti-citrullinated peptide antibodies test was done by using enzyme-linked immunosorbent assay (ELISA).

\section{Ocular Examination}

Ocular examination was done to evaluate for the various ocular manifestations such as dry eyes KCS, scleritis, episcleritis, peripheral ulcerative keratitis, anterior uveitis. It included best corrected visual acuity, testing for color vision, detailed slit lamp examination of the anterior segment, detailed fundus examination, refraction, intraocular pressure measurement, and tests for dry eyes. Visual fields were performed. Basal Schirmer's test was performed using Schirmer strips of $35 \mathrm{~mm}$ in length and $5 \mathrm{~mm}$ in width. The Schirmer strip was folded $5 \mathrm{~mm}$ from one end and inserted at the junction of the middle and outer third of the lower lid taking care not to touch the cornea. The patient was asked to keep the eyes gently closed. After $5 \mathrm{~min}$, the strip was removed and the amount of wetting from the fold measured. The value of $<10 \mathrm{~mm}$ at the end of $5 \mathrm{~min}$ was considered abnormal.

\section{Results}

Sixty RA patients were evaluated; 5 males, 55 females. The mean \pm standard deviation age of the patients was $50.46 \pm$ 11.457 years. The most frequent age group was (51-60) which is $18(30.00 \%)$ of the patients and $50 \%$ of them had ocular manifestations while the age group (31-40) had $11(64.71 \%)$ associated with ocular manifestations (Table 1). There is obvious female predominance 55 (91.67\%) were included, while male represents $5(8.33 \%)$, $65.5 \%$ of the female group has ocular manifestations, while $60.0 \%$ of the male group has ocular manifestations. Statistically, it is not significant $(P=1.000)$ as shown in Table 2.

Table 1: Age distribution in patients with ocular manifestations of rheumatoid arthritis.

\begin{tabular}{lcccccc}
\hline \multirow{2}{*}{ Age years } & No. & $(\%)$ & \multicolumn{2}{c}{ Ocular manifestations } \\
& & & No. & $(\%)$ & No. & (\%) \\
\hline $31-40$ & 17 & $(28.33)$ & 11 & $(64.71)$ & 6 & $(35.29)$ \\
$41-50$ & 14 & $(23.33)$ & 10 & $(71.43)$ & 4 & $(28.57)$ \\
$51-60$ & 18 & $(30.00)$ & 9 & $(50.0)$ & 9 & $(50.0)$ \\
$61-70$ & 10 & $(16.67)$ & 8 & $(80.0)$ & 2 & $(20.0)$ \\
$>70$ & 1 & $(1.67)$ & 1 & $(100)$ & 0 & $(0.0)$ \\
Total & 60 & $(100)$ & 39 & $(65.0)$ & 21 & $(35.0)$ \\
\hline
\end{tabular}

Table 2: Ocular manifestations of rheumatoid arthritis by gender.

\begin{tabular}{lccccccc}
\hline \multirow{2}{*}{ Gender } & \multicolumn{3}{c}{ Ocular manifestations } & \multicolumn{2}{c}{ Total } & \multirow{2}{*}{ P value } \\
& Nositive & $\mathbf{( \% )}$ & No. & (\%) & No. & (\%) & \\
\hline Male & 3 & 60.0 & 2 & 40.0 & 5 & 100.0 & \multirow{2}{*}{1.000} \\
Female & 36 & 65.5 & 19 & 34.5 & 55 & 100.0 & \\
Total & 39 & 65.0 & 21 & 35.0 & 60 & 100.0 & \\
\hline
\end{tabular}


According to the frequency of eye complications, we had $39(65.0 \%)$ of the patients with eye complications and 21 $(35.0 \%)$ had no eye complications and most frequent complication was dry eyes 30(50.0\%). Details are shown in Table 3.

Relationship between DAS28 and ocular manifestations

There was only one patient in mild group did not have ocular manifestations, in moderate group there were $21(65.6 \%)$ of the patients got ocular manifestations and $11(34.4 \%)$ of the patients with no ocular manifestations, in high group there were $18(66.7 \%)$ of the patients got ocular manifestations and $9(33.3 \%)$ of them with no ocular manifestations. This difference was statistically not significant $(P=0.529)$ as shown in Table 4.

Relationship between anti ccp and ocular manifestations

The positive group there were $32(76.2 \%)$ of the patients got ocular manifestations and $10(32.8 \%)$ of the patients with no ocular manifestations, while in negative group $7(38.9 \%)$ of the patients got ocular manifestations and $11(61.1 \%)$ of the patients with no ocular manifestations. The difference was statistically significant $(P=0.006)$ as shown in Table 5.

Table 3: Prevalence of ocular manifestations in RA patients.

\begin{tabular}{llcc}
\hline \multicolumn{2}{c}{ Ocular manifestations } & No. & (\%) \\
\hline 1 & Dry eyes & 30 & 50.0 \\
2 & Anterior uveitis & 4 & 6.6 \\
3 & Episcleritis & 3 & 5.0 \\
4 & Posterior uveitis & 1 & 1.7 \\
5 & Keratoconjunctivitis sicca & 1 & 1.7 \\
6 & No eye manifestation & 21 & 35.0 \\
& Total & 60 & 100.0 \\
\hline
\end{tabular}

Table 4: Relationship between DAS28 and ocular manifestations.

\begin{tabular}{|c|c|c|c|c|c|c|c|c|}
\hline \multirow{3}{*}{ DAS28 } & & \multicolumn{6}{|c|}{ Ocular manifestations } & \multirow{3}{*}{$P$ value } \\
\hline & & \multicolumn{2}{|c|}{ Present } & \multicolumn{2}{|c|}{ Absent } & \multicolumn{2}{|c|}{ Total } & \\
\hline & & No. & $\%$ & No. & $\%$ & No. & $\%$ & \\
\hline \multirow[t]{3}{*}{ DAS28 } & Mild (2.6-3.2) & 0 & .0 & 1 & 100.0 & 1 & 100.0 & \\
\hline & Moderate(3.3-5.1) & 21 & 65.6 & 11 & 34.4 & 32 & 100.0 & 0.529 \\
\hline & $\operatorname{High}(>5.1)$ & 18 & 66.7 & 9 & 33.3 & 27 & 100.0 & \\
\hline Total & & 39 & 65.0 & 21 & 35.0 & 60 & 100.0 & \\
\hline
\end{tabular}

Table 5: Relationship between anti ccp and ocular manifestations.

\begin{tabular}{lccccccc}
\hline \multirow{2}{*}{ Anti ccp } & \multicolumn{9}{c}{ Eye complication } & \multicolumn{2}{c}{ Total } & \multirow{2}{*}{ P value } \\
& No. & $\%$ & No. & $\%$ & No. & $\%$ & \\
\hline Positive & 32 & 76.2 & 10 & 23.8 & 42 & 100.0 & 0.006 \\
Negative & 7 & 38.9 & 11 & 61.1 & 18 & 100.0 & \\
Total & 39 & 65.0 & 21 & 35.0 & 60 & 100.0 & \\
\hline
\end{tabular}


https:/ / doi.org/ 10.15218/ zjms.2017.024

Relationship between DMARD alone, DMARD +Biological Agents effects and ocular manifestations in RA patients

In the group whose using DMARD alone, there were $19(63.3 \%)$ of them had ocular manifestations, and $11(36.7 \%)$ of them had no ocular manifestations, in the other group that using DMARD and biological agents there were $20(66.7 \%)$ of them had ocular manifestations and 10(33.3\%) of them had no ocular manifestations. The difference was statistically not significant $(P=0.787)$ as shown in Table 6.

\section{Discussion}

In this study, the ocular manifestations were found in 39 of the 60 patients studied which is $65 \%$ of the studied population while in another study they found from 70 patients only $19 \%$ of the cases had ocular manifestations. ${ }^{13}$ This indicates that ocular lesions are important extra-articular manifestations in rheumatoid arthritis. The most common age group that had ocular manifestations with RA was 31-40 years, which is nearly going with study done by Gordana Zlatanović in which the result was the more frequency of ocular manifestations in RA aged 31-50 years. ${ }^{14}$ There is female predominance $55(91.67 \%)$ of the patients, while male represent 5 (8.33\%), $65.5 \%$ of female group has ocular manifestations, while $60.0 \%$ of male group has ocular manifestations and this goes with the study done by Gordana Zlatanović in which females were also more common than males, nearly same percentage. ${ }^{14}$
The most common ocular manifestation was dry eyes $50 \%$ (30 cases) followed by anterior uveitis $6.6 \%$, episcleritis $5 \%$, and keratoconjunctivitis sicca and posterior uveitis $1.7 \%$, which goes with the study done by $\mathrm{C}$. Charanya et al. which was their result $64 \%$ of the patients got ocular manifestations. And common ocular manifestation was dry eye $44 \%$ (22 cases) followed by episcleritis, scleritis and corneal ulcer, viral keratitis, and conjunctivitis. ${ }^{15}$ Our study revealed that there was no statistically significant relationship between severity of the RA disease which was estimated by DAS28-ESR formula and ocular manifestations, which is comparable to the study done by Zahra Zakeri et al. which revealed there was no relationship between severity of RA and ocular manifestation (dry eye syndrome. ${ }^{16}$ While there is study done by Gilbo et al. in 2001 concluded that dry eye syndrome in RA patients reflect more activity of disease and there was relationship between ocular manifestations (dry eye), ESR, and number of painful joints. ${ }^{17}$ In our study we found that there is statistically significant relationship between the Anti-CCP antibodies titer and presence of ocular manifestations in RA patients which are comparable to the studies done by Itty et al. and ammapati Paul Pandian Vignesh and renuka Srinivasan whose found that there is strong association between the presence of anti-CCP antibodies and the

Table 6: Relationship between DMARD alone DMARD +Biological Agents effects and ocular manifestations in RA patients.

\begin{tabular}{lccccccc}
\hline \multirow{2}{*}{$\begin{array}{l}\text { DMARD or DMARD } \\
\text { +biological agent }\end{array}$} & \multicolumn{4}{c}{ Ocular manifestations } & \multicolumn{2}{c}{ Total } & \multirow{2}{*}{ Present } \\
& No. & $\%$ & Absent & & & \\
& 19 & 63.3 & 11 & 36.7 & 30 & 100.0 & \\
\hline DMARD alone & 20 & 66.7 & 10 & 33.3 & 30 & 100.0 & 0.787 \\
DMARD \& biological agents & 39 & 65.0 & 21 & 35.0 & 60 & 100.0 & \\
Total & & & & & & & \\
\hline
\end{tabular}


presence of ocular manifestations of RA. ${ }^{11,18}$ According to use of DMARD alone or DMARD and Biological Agents as a treatment for articular and extra-articular manifestations in RA patients, we found that there is no statistical significance relationship between the curable effects of them and ocular manifestations in RA patient, while studies were done by Gordana Zlatanović et al. and others show that (DMARDs) are necessary to improve tear production and to resolve severe ocular complications in RA patients like Cyclosporine $\mathrm{A}$, or a monoclonal antibody to TNF-alpha such as infliximab. ${ }^{19,21}$

\section{Conclusion}

We conclude from this study that the ocular manifestations are a significant part of the extra-articular manifestation of RA, dry eye is the most common ocular manifestation. The Anti-CCP antibodies titer is a sensitive marker for detection of ocular manifestations in RA Patients. This variety of RA activity is not an indicator for occurrence ocular complications in a patient with RA. Although the new DMARDs and biological therapies have dramatic effects in the treatment of RA patients, this study found that they provide no significant efficacy in treatment or prevent the occurrence of ocular manifestations in RA patients. Further longitudinal studies and increase the number of population of the studies to find out more ocular involvement in RA patients and the effects of new drugs (DMARDs and biological agents) in preventing or decreasing the occurrence of ocular complications in RA patients.

\section{Conflicts of interest}

The authors report no conflicts of interest.

\section{References}

1. Macgregor AJ, Snieder $H$, Rigby AS, Koskenvuo M, Kaprio J, Silman AJ. Characterizing the quantitative genetic contribution to rheumatoid arthritis using data from twins. Arthritis Rheum 2000; 43:30-7.

2. Sahatçiu-Meka V, Rexhepi S, Manxhuka-Kërliu S, Rexhepi M. Extraarticular manifestation of seronegative and seropositive reumathoid arthritis Bosn. J Basic Med Sci 2010;10(1):27-31.

3. Lilleby V, Gran JT. Systemic rheumatoid arthritis: Tidsskr Nor Laegeforen2007; 117(29):4223-5.

4. Cimmino MA, Salvarani $C$, Macchioni $P$. Extra-articular manifestations in $Y Z$ Italian patients with rheumatoid arthritis. Rheumatol Int 2000; 19(6):213-7.

5 . Kanski JJ. The eye in systemic disease. London: Butterworts; 2004.

6. Whitson WE, Krachmer JH. Adult rheumatoid arthritis. In: Gold DH, Weingeist TA, editors. The eye in systemic disease. Philadelphia: JB. Lippincott; 2003. P. 127-208.

7. Hakin KN, Ham J, Lightman SL. Use of orbital floor steroids in the management of patients with uniocular non-necrotizing scleritis. Ophthaloml 2005; 75(6):337-9.

8. Galor A, Jabs DA, Leder HA, Kedhar SR, Dunn JP, Peters GB. Comparison of antimetabolite drugs as corticosteroid-sparing therapy for noninfectious ocular inflammation. Ophthalmol 2008; 115(10):1826-32.

9. Nicki R, Colledge Brian $R$, Walker Stuart $H$, Ralston. Davidson's principle and practise of medicine. 21 st edition. In: Doherty M, Ralston S.H, editors. Musculoskeletal disease. Edinburg: Academic press; 2010. p. 1090.

10. John $H$, Leslie $J$, Patience $H$. Primer on rheumatic disease. $13^{\text {th }}$ ed. In : Frank B, Gerd R.B, editors .Glucocorticoids. Boston: MA, USA; 2013. p. 648.

11. Itty S, Pulido JS, Bakri SJ, Baratz KH, Matteson EL, Hodge DO. Anti-Cyclic Citrullinated Peptide, Rheumatoid Factor, and Ocular Symptoms Typical of Rheumatoid Arthritis. Trans Am Ophthalmol Soc 2008; 106:75-81.

12. El-Banna H, Jiman-Fatani A. Anti-cyclic citrullinated peptide antibodies and paraoxonase -1 polymorphism in rheumatoid arthritis. BMCMusculoskelet Disord 2014;15: 379.

13. Zoto1 A, Selimi B. Ocular Involvement in Patients with Rheumatoid Arthritis. Ophthalmol Research J 2015; 4(4):99-103.

14. Zlatanovic G, Selionvic D, Cekic S, Zivkovic M, Jocic J, Zlatanovic M. Ocular manifestation of rheumatoid arthritis-different forms and frequency. Bosnian Journal of Basic Medical Science 2010; 10 (4): 323-7.

15. Charanya C. Ocular Manifestation in Rheumatoid Arthritis Patients Presenting to Tertiary Care Hospital in South India. International Journal of Scientific Study 2015.(3)8.

16. Zakeri Z, Parsa M, Zanjani H, Ansarimoghaddam A, Sandoughi M, Aminifard M, et al. Relationship Between Severity of RA and Dry Eye. Health Scope 2012; 1(4):186-8.

17. Gilboe IM, Kvien TK, Uhlig T, Husby G. Sicca symptoms and secondary Sjögren's syndrome in systemic lupus erythematosus: comparison with rheumatoid arthritis and 
correlation with disease variables. Rheum Disease 2001; 60(12):1103-9.

18. Paul A, Vignesh $P$, Srinivasan R. Ocular manifestations of rheumatoid arthritis and their correlation with anti-cyclic citrullinated peptide antibodies. Clin Ophthalmol 2015; 9: 393-7.

19. Sobrin L, Kim EC, Christen W, Papadaki T, Letko E, Foster CS. Infliximab therapy for the treatment of refractory ocular inflammatory disease. Arch Ophthalmol 2007; 125(7):895-900.

20. Sobrin L, Christen W, Foster CS. Mycophenolate mofetil after methotrexate failure or intolerance in the treatment of scleritis and uveitis. Ophthalmol 2008; 115(8):1416-21.

21. Papaliodis GN, Chu D, Foster CS. Treatment of ocular inflammatory disorders with daclizumab. Ophthalmology 2003; 110(4):786-9. 